\title{
Reproducibility of energy and macronutrient intake and related substrate oxidation rates in a buffet-type meal
}

\author{
Konstantinia Arvaniti, Denis Richard and Angelo Tremblay* \\ Center for Research on Energy Metabolism, Laval University, Quebec, Canada \\ (Received 25 March 1999 - Revised 28 September 1999 - Accepted 10 October 1999)
}

\begin{abstract}
The aim of this present study was to determine the reliability of a buffet-type meal as a measure of spontaneous energy and macronutrient intake. In addition, we evaluated the short-term effects of diet on the composition of the substrate mix oxidized postprandially. Fourteen male subjects had ad libitum access to a variety of foods from a buffet-type meal offered in the laboratory during two identical sessions. The foods comprising the test meal had varying amounts of protein, lipid and carbohydrate. The results showed that there were significant intraclass correlations $\left(r_{i}\right)$ for energy $\left(r_{i} 0.97, P=0.0001\right)$, lipid $\left(r_{i} 0.97, P=0.0001\right)$, carbohydrate $\left(r_{i} 0.92, P=0.0003\right)$ and protein $\left(r_{i} 0.82, P=0.0072\right)$ intake between the two meal sessions. Hunger and fullness levels measured immediately before and during $4 \mathrm{~h}$ after the meal were identical under the two conditions. In addition, there was no significant difference between the two sessions for RQ and resting energy expenditure, which showed significant reproducibility for measurements obtained immediately before, immediately after, as well as $30 \mathrm{~min}$ after, the buffet. This present study demonstrates the high reproducibility of energy and macronutrient intake and oxidation rate values obtained with a buffet-type meal in healthy male subjects and suggests that the use of this test is a reliable method for assessment of macronutrient preferences in the laboratory.
\end{abstract}

Food intake: Fullness: Hunger: Respiratory quotient: Energy expenditure

It has been suggested that the administration of a buffet-type meal in the laboratory could be an appropriate method for the accurate measurement of food intake (Rolls \& Hammer, 1995; Tremblay \& Saint-Pierre, 1996) because it offers an experimental context where energy intake and macronutrient preferences can be assessed. Even if standard buffet-type meals are often used to assess food intake (Rolls et al. 1994; Cook et al. 1997; Imbeault et al. 1997), their reproducibility in terms of energy and macronutrient intake has not been documented in the literature. The assessment of the reproducibility of a buffet meal is important because humans vary their food intake and nutrient selection from day-to-day (Tremblay et al. 1983; Obarzanek \& Levitsky, 1985). This intra-individual variation can negatively affect the validity of studies using a buffet-type paradigm. Thus, a first aim of this present study was to evaluate the reproducibility of energy and macronutrient intake using a buffet-type meal.

The energy-macronutrient balance issue has been the object of numerous research observations over the last decades. This area of investigation was led by Flatt (Flatt et al. 1985; Flatt, 1995a,b) who emphasized the large difference in the accuracy with which carbohydrate and lipid balance are maintained stable. Specifically, it has been shown that an acute increase in lipid intake in response to a meal test does not result in an acute increase in lipid oxidation (Flatt et al. 1985; Rising et al. 1992; Horton et al. 1995; Larson et al. 1995b). Conversely, an increase in carbohydrate intake, be it small or more substantial, rapidly increased carbohydrate oxidation (Rising et al. 1992; Thomas et al. 1992; Larson et al. 1995b; Stubbs et al. 1997). To further investigate this issue, we took advantage of the present paradigm to evaluate the relationship between diet composition when one has free access to food in the context of a buffet-type meal and the composition of the substrate mix oxidized early after food intake in order to evaluate short-term macronutrient oxidation.

\section{Methods \\ Subjects}

Fourteen men, aged between 26 and 48 years, were recruited through advertisements and gave their written consent to participate in this study. Their physical characteristics are shown in Table 1. They were non-smokers, healthy, and sedentary to moderately active individuals. They were taking 
Table 1. Physical characteristics of the subjects $(n 14)$

\begin{tabular}{lcl}
\hline Variables & Mean & SEM \\
\hline Age (years) & 38.3 & 2.1 \\
Body mass $(\mathrm{kg})$ & 74.5 & 2.6 \\
Height $(\mathrm{m})$ & 1.757 & 0.017 \\
Body fat $(\%)$ & 19.0 & 1.8 \\
BMl $\left(\mathrm{kg} / \mathrm{m}^{2}\right)$ & 24.3 & 0.7 \\
\hline
\end{tabular}

no medication and they were used to eating at breakfast and lunchtime. Their body weight was stable during the year preceding the study. Before initiating the protocol, all subjects completed a visual analogue scale (VAS) to ensure that they liked the foods served in the test meals. To be eligible to take part in the study, a subject had to rate at least $80 \%$ of foods offered in the buffet at $50 \mathrm{~mm}$ or more on the $100 \mathrm{~mm}$ VAS (Rolls et al. 1994). Subjects were requested to avoid vigorous activities for at least $2 \mathrm{~d}$ before each experimental session. Although all subjects signed a consent form before the experimental protocol, they were not informed of the real purpose of this study. The consent form and the experimental protocol had previously been reviewed and approved by the Laval University Medical Ethics Committee.

\section{Experimental sessions}

Each subject was tested individually in two identical sessions
(A and B) separated by at least $7 \mathrm{~d}$. Subjects were instructed to eat as usual for the period covered by the protocol but to abstain from alcohol the evening before each experimental session. On each day of testing, the subject was asked to eat at home at 07.15 hours a standardized breakfast $(2005 \mathrm{~kJ})$ prepared by a dietitian from our team and nothing else except water was allowed until the buffet. The session started at 11.20 hours when the subject arrived at the laboratory. After a $30 \mathrm{~min}$ period of rest in the supine position, resting energy expenditure (REE) was measured for $15 \mathrm{~min}$. At about 12.10 hours, a cold buffet-type meal comprising a variety of foods was offered and the subject was instructed to eat ad libitum (Table 2). Subjects took 20$40 \mathrm{~min}$ to eat their meal, except for one subject who took $60 \mathrm{~min}$ to eat ad libitum. Portions of each food were larger than the expected intake by the subject. Table 2 shows that there was a large diversity in the protein, lipid and carbohydrate content of foods in order to facilitate the detection of macronutrient preferences. All foods were weighed before the buffet and food items that were not consumed were reweighed after the end of the buffet to the nearest $g$ to quantify the exact intake of each type of food. Energy, protein, lipid and carbohydrate intake were calculated using the Canadian Nutrient File (Department of National Health and Welfare Canada, Ottawa, Canada) and/or information on food labels. Immediately after the lunch, REE was measured for two 15 min periods with an interval rest

Table 2. Energy content and macronutrient composition of the food items presented in the buffet-type meal ${ }^{*}$

\begin{tabular}{|c|c|c|c|c|c|}
\hline Food item & $\begin{array}{l}\text { Initial amount } \\
\text { (g) }\end{array}$ & $\begin{array}{l}\text { Energy } \\
(\mathrm{kJ} / \mathrm{kg})\end{array}$ & $\begin{array}{c}\text { Protein } \\
(\mathrm{g} / \mathrm{kg})\end{array}$ & $\begin{array}{l}\text { Lipid } \\
(\mathrm{g} / \mathrm{kg})\end{array}$ & $\begin{array}{c}\text { Carbohydrate } \\
(\mathrm{g} / \mathrm{kg})\end{array}$ \\
\hline Sliced turkey breast & 130 & 3930 & 160 & 34 & 0 \\
\hline Salmon and spinach mousse & 90 & 10833 & 117 & 233 & 27 \\
\hline Liver pâté & 70 & 13350 & 142 & 280 & 15 \\
\hline Sliced ham & 150 & 5480 & 194 & 50 & 10 \\
\hline Sliced Swiss Gruyère cheese & 100 & 17286 & 298 & 323 & 4 \\
\hline Mozzarella cheese & 100 & 11718 & 275 & 171 & 31 \\
\hline Cottage cheese & 100 & 3384 & 117 & 20 & 40 \\
\hline Butter & 40 & 29990 & 9 & 811 & 1 \\
\hline Mayonnaise & 60 & 30630 & 11 & 804 & 11 \\
\hline Italian dressing & 60 & 26110 & 2 & 690 & 52 \\
\hline Mustard & 30 & 3140 & 47 & 44 & 64 \\
\hline Ketchup & 40 & 4350 & 15 & 4 & 273 \\
\hline White bread & 150 & 11300 & 87 & 32 & 505 \\
\hline Wheat bread & 150 & 10170 & 105 & 30 & 477 \\
\hline Soda crackers & 100 & 18400 & 104 & 132 & 708 \\
\hline Sliced lettuce & 60 & 670 & 16 & 2 & 24 \\
\hline Sliced tomato & 100 & 880 & 9 & 3 & 46 \\
\hline Baby cut carrots & 150 & 1800 & 10 & 2 & 101 \\
\hline Cored and sliced orange & 100 & 1970 & 9 & 1 & 118 \\
\hline Sliced red apple & 100 & 2470 & 2 & 4 & 153 \\
\hline Butter shortbread cookies & 70 & 20840 & 72 & 231 & 651 \\
\hline Chocolate-almond cookies & 100 & 19700 & 41 & 240 & 620 \\
\hline Fruit salad yogurt, stirred & 250 & 4050 & 39 & 15 & 168 \\
\hline Milk (10 g fat/l) & 1000 & 1754 & 33 & 11 & 47 \\
\hline Milk (20 g fat/l) & 1000 & 2095 & 33 & 19 & 44 \\
\hline Milk (30 g fat/l) & 1000 & 2549 & 33 & 33 & 47 \\
\hline Orange juice & 1000 & 1826 & 8 & 2 & 109 \\
\hline Coca-cola & 355 & 1720 & 0 & 0 & 104 \\
\hline 7-up & 355 & 1674 & 0 & 0 & 104 \\
\hline Regular crisps & 60 & 23214 & 61 & 393 & 500 \\
\hline Water & 1000 & & & & \\
\hline
\end{tabular}

* Energy, protein, lipid and carbohydrate content were calculated using the Canadian Nutrient File (Department of National Health and Welfare Canada, Ottawa, Canada) and/or information on food labels. 
period of $15 \mathrm{~min}$. Immediately before and after the buffet and every hour after the buffet for a period of $4 \mathrm{~h}$, subjects completed a $100 \mathrm{~mm}$ VAS for the determination of hunger and fullness. Urine was collected at the end of the experimental session for Kjeldahl $\mathrm{N}$ analysis to calculate urinary $\mathrm{N}$ excretion.

\section{Measurements}

Body fat mass was determined using underwater weighing. The Siri equation (Siri, 1956) was used to estimate percentage body fat from body density. Residual lung volume was determined before hydrostatic weighing with the He dilution technique (Meneely \& Kaltreider, 1949). REE and RQ were determined by respiratory gas exchange using an opencircuit computerized indirect calorimeter connected to a mouthpiece system. $\mathrm{O}_{2}$ and $\mathrm{CO}_{2}$ concentrations were determined by non-dispersive i.r. analysis (Uras 10 E, Hartmann $\&$ Braun, Frankfurt, Germany) whereas pulmonary ventilation determination was assessed with a S-430A measurement system (KL Engineering, Ventura, CA, USA). REE and RQ were evaluated for each subject three times during each session, following a $30 \mathrm{~min}$ rest in the supine position before the buffet-type meal, and immediately after and $30 \mathrm{~min}$ after the buffet. Measurements were taken over $15 \mathrm{~min}$ periods and the average of the last $10 \mathrm{~min}$, when a steady state was established, was used to calculate REE and RQ. Substrate oxidation rates were calculated from consumed $\mathrm{O}_{2}$ and $\mathrm{CO}_{2}$ volume and urinary $\mathrm{N}$ excretion using classical equations (Jéquier et al. 1987).

\section{Statistical analysis}

For energy and macronutrient intake, ANOVA was used to estimate the reproducibility of the two sessions (interreproducibility) by comparison between the group mean for a given variable between sessions $\mathrm{A}$ and $\mathrm{B}$. The reproducibility of each subject (intra-subject reproducibility) refers to the correspondence of each subject measurements between sessions and was evaluated by linear correlation analysis and intraclass correlation coefficients $\left(r_{i}\right)$ between the individual values in sessions A and B. Additional information concerning variation of measurements between subjects and within a given individual was obtained by estimation of inter-subject (between) and intrasubject (within) variability which was expressed as CV $\left(\mathrm{CV}_{\mathrm{bs}}\right.$ and $\mathrm{CV}_{\mathrm{ws}}$ respectively) for energy and macronutrient intake. For variables measured over time, repeated-measure ANOVA with session and time as the within-subject measurements was used to determine whether there were differences between sessions A and B over time.

\section{Results}

Table 3 shows that there were no significant differences in mean ad libitum energy and macronutrient intake between sessions A and B. Furthermore, a significant positive correlation was observed between the two sessions for energy, carbohydrate, lipid and protein intake and food quotient. The $\mathrm{CV}_{\mathrm{bs}}$ of about $40 \%$ for energy and macronutrient intake, which demonstrates that each subject showed individual difference in intake responses to the buffet-type 

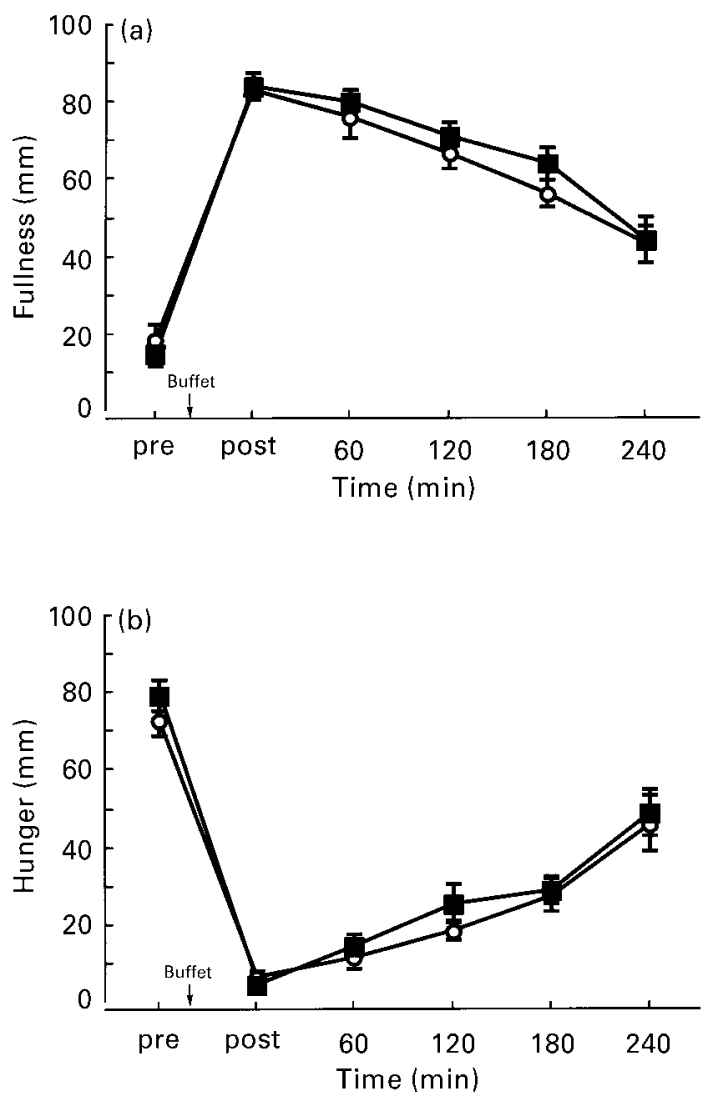

Fig. 1. Variations in (a) fullness and (b) hunger over time, as measured by a visual analogue scale, immediately before (pre) and 0 to 240 min after two sessions of self-selection from a buffet-type meal. Values are means for fourteen male subjects with standard errors of the mean represented by vertical bars. Repeated-measure ANOVA with session (S) and time (T) as the within-subject measurements was used to determine whether there were differences between sessions $A(O)$ and $B(\boldsymbol{\square})$ over time and the interaction effect of $S$ and $\mathrm{T}(\mathrm{S} \times \mathrm{T})$. Fullness: $\mathrm{S}, P=0.48 ; \mathrm{T}, P=0.0001$ and $\mathrm{S} \times \mathrm{T}$, $P=0.68$. Hunger: $\mathrm{S}, P=0.44 ; \mathrm{T}, P=0.0001$ and $\mathrm{S} \times \mathrm{T}, P=0.79$.

meal, was much higher than the intra-subject variability $\left(\mathrm{CV}_{\mathrm{ws}}\right.$ of about $\left.10 \%\right)$ which demonstrates an individual reproducibility in energy and macronutrient intake between sessions A and B. The lack of significant differences between the two sessions in fullness and hunger measured over time before and after the buffet also revealed significant reproducibility (Fig. 1). Indeed, in response to the meal, fullness and hunger significantly fluctuated over time and no session $\times$ time interaction was observed. A strong linear correlation was shown between individual measurements in sessions $\mathrm{A}$ and $\mathrm{B}$ for fullness $\left(r_{i} 0.99, P=0.0001\right)$ and hunger $\left(r_{i} 0.98, P=0.0001\right)$ levels for measurements obtained over time by VAS immediately before (pre) and 0-240 min after the buffet. There was no significant correlation between hunger and energy intake within session A or B immediately before and immediately after the meal.

As expected, RQ and REE significantly increased after the buffet because of an increase in carbohydrate oxidation (Fig. 2). An inter-reproducibility of the two sessions in RQ and REE (no significant difference between the two
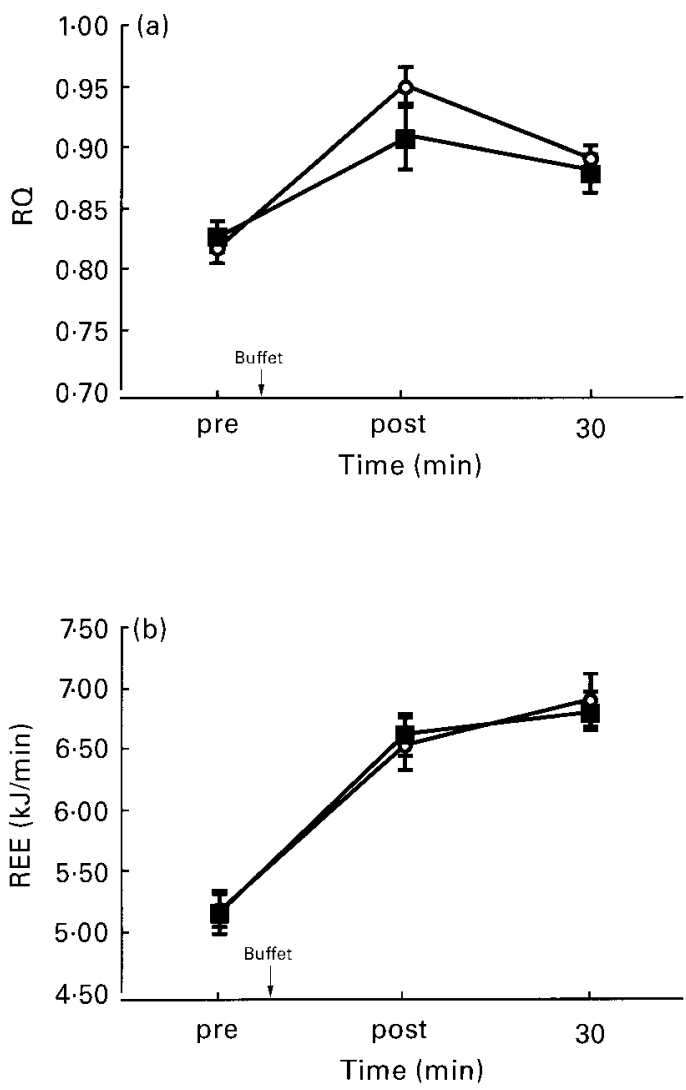

Fig. 2. Variations in (a) respiratory quotient $(R Q)$ and (b) resting energy expenditure (REE) over time immediately before (pre), immediately after (post) and $30 \mathrm{~min}$ (30) after two sessions of self-selection from a buffet-type meal. Values are means for fourteen male subjects with standard errors of the mean represented by vertical bars. Repeated-measure ANOVA with session (S) and time $(T)$ as the within-subject measurements was used to determine whether there were differences between sessions $A(O)$ and $B(\boldsymbol{\square})$ over time and the interaction effect of $S$ and $\mathrm{T}(\mathrm{S} \times \mathrm{T})$. RQ: $\mathrm{S}, P=0.33 ; \mathrm{T}, P=0.0001$ and $\mathrm{S} \times \mathrm{T}, P=0.18$. REE: $\mathrm{S}, P=0.96 ; \mathrm{T}, P=0.0001$ and $\mathrm{S} \times \mathrm{T}, P=0.80$.

sessions) and significant intraclass correlation (intra-subject reproducibility) between individual measurements in the two sessions $\left(r_{i} 0.90, P=0.0001\right.$ for RQ and $r_{i} 0.98, P=$ 0.0001 for REE) for values obtained over time immediately before (pre), immediately after (post) and $30 \mathrm{~min}$ after the buffet were also observed. Carbohydrate oxidation significantly increased while lipid oxidation decreased immediately after the buffet and a lack of significant differences between sessions $\mathrm{A}$ and $\mathrm{B}$ for carbohydrate and lipid oxidation was also observed (Fig. 3). There was no interaction effect of session and time on RQ, REE, as well as carbohydrate and lipid oxidation. As for macronutrient intake, there was a significant correlation in carbohydrate $\left(r_{i} 0 \cdot 95, P=0.0001\right)$ and lipid $\left(r_{i} 0 \cdot 98, P=0.0001\right)$ oxidation individual measurements between the two sessions for values obtained immediately before, after (post) and 30 min after the buffet. In addition, there was no relationship between lipid oxidation and lipid intake immediately before, immediately after as well as $30 \mathrm{~min}$ after the buffet. Conversely, carbohydrate oxidation positively correlated with carbohydrate intake immediately after (post) and $30 \mathrm{~min}$ after the buffet (Table 4). 

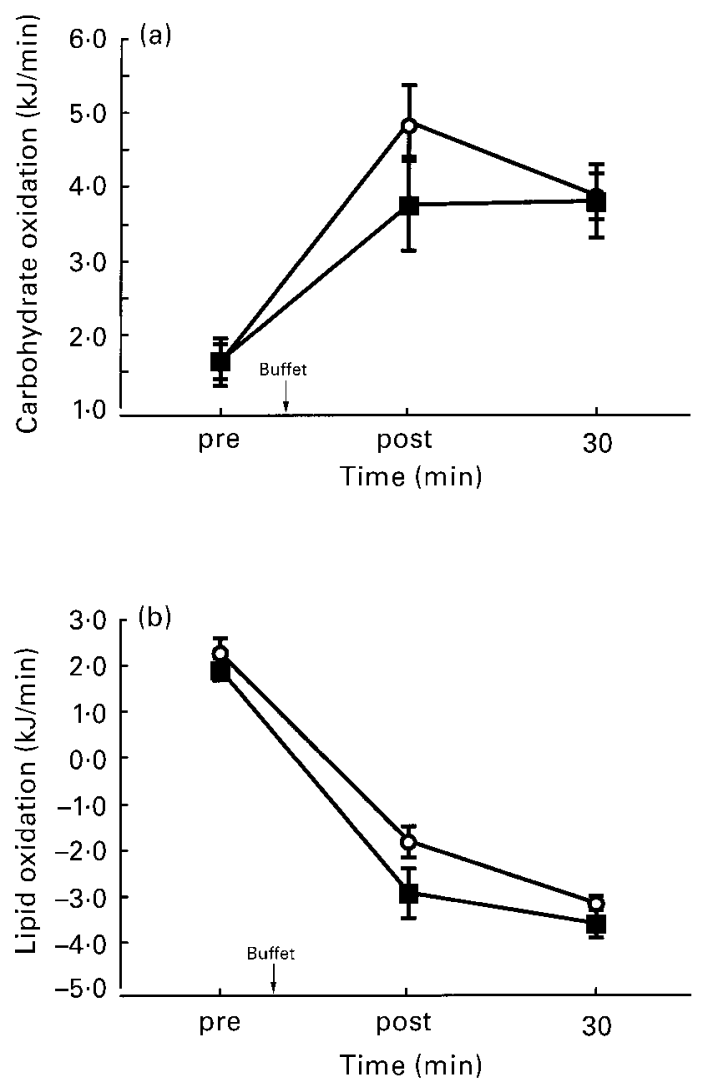

Fig. 3. Variations in (a) carbohydrate and (b) lipid oxidation over time immediately before (pre), immediately after (post) and $30 \mathrm{~min}$ (30) after two sessions of self-selection from a buffet-type meal. Values are means for fourteen male subjects with standard errors of the mean represented by vertical bars. Repeated-measure ANOVA with session (S) and time (T) as the within-subject measurements was used to determine whether there were differences between sessions $A(O)$ and $B(\boldsymbol{\square})$ over time and the interaction effect of $S$ and $T(S \times$ T). Carbohydrate oxidation: $\mathrm{S}, P=0.19 ; \mathrm{T}, P=0.0001$ and $\mathrm{S} \times \mathrm{T}, P=$ 0.18 . Lipid oxidation: $\mathrm{S}, P=0.08 ; \mathrm{T}, P=0.0001$ and $\mathrm{S} \times \mathrm{T}, P=0.71$.

\section{Discussion}

The results of this present study provide evidence that the use of a buffet-type meal is a reproducible method to assess macronutrient preferences in the laboratory. This was mainly supported by the lack of significant differences between the averages in sessions A and B (inter-reproducibility) for energy and macronutrient intake and by significant intraclass correlations for all variables shown in Table 3 (intra-reproducibility). These results suggest that food intake tends to remain stable from one session to the other when a buffet-type meal is offered ad libitum. Of particular interest was the fact that energy and lipid intake were strongly reliable as the intraclass correlation coefficient for these two variables was very high, which means that subjects had the same total energy and lipid intake in the two sessions. To generalize these observations that were made in healthy male subjects, this study should be repeated in women, adolescents or persons suffering from extreme conditions such as obesity or anorexia where food intake is altered.

The low $\mathrm{CV}_{\text {ws }}$ of $10 \%$ represents the low variability of energy and macronutrient intake of each subject's food intake between the two sessions, supporting the reproducibility of a buffet-type meal, and the high $\mathrm{CV}_{\mathrm{bs}}$ of $40 \%$ underlines the different pattern of food selection and the biological differences between subjects. Indeed, this confirms the idea that even in the controlled and restricted environment of a laboratory, the context of a buffet-type meal allows subjects to express their own individual food selection pattern. The findings of this study are in agreement with results reported by Obarzanek \& Levitsky (1985) who also found $a \mathrm{CV}_{\mathrm{ws}}$ of $10 \%$ when subjects ate in the laboratory and demonstrated that eating in the laboratory is representative of habitual food intake. Finally, the significant reliability of fullness and hunger, two important indicators of feeding behaviour that are generally used to provide some complementary information when predicting subsequent food intake, yielded additional evidence that food intake was reproducible in the buffet-type meal.

The distribution of energy intake among carbohydrate, lipid and protein was representative of a western diet. Lipid and carbohydrate intake during buffets both corresponded to 41-42\% energy intake, which is comparable to a North American diet (Friedman, 1990). These results also suggest that the buffet-type meal is not only reliable but also represents a satisfactory testing condition to measure real macronutrient composition of daily food intake. Although the use of a buffet to detect energy and macronutrient intake is not fully representative of free-living conditions, it allows precise measurements of energy and macronutrient intake over short periods of time. As previously investigated (Westerterp-Plantenga et al. 1996; Bellisle et al. 1998), it is useful to analyse foods further on the basis of their taste composition since a major determinant of food selection seems to be individual food preferences (Stubbs et al. 1999). In the present study, the buffet was composed of foods chosen to represent free-living conditions and to investigate energy and macronutrient intake and not food selection related to taste. Further research would be relevant to investigate not only macronutrient intake but also taste that always plays a role in influencing food choice and selection patterns.

Table 4. Relationships between carbohydrate oxidation and carbohydrate intake and between lipid oxidation and lipid intake for the mean of two sessions of self-selection from a buffet-type meal $(n 14)$

\begin{tabular}{|c|c|c|c|c|c|c|}
\hline & \multicolumn{2}{|c|}{$\begin{array}{l}\text { Immediately before } \\
\text { the buffet }\end{array}$} & \multicolumn{2}{|c|}{$\begin{array}{l}\text { Immediately after } \\
\text { the buffet }\end{array}$} & \multicolumn{2}{|c|}{$\begin{array}{l}30 \text { min after } \\
\text { the buffet }\end{array}$} \\
\hline & $r$ & $P$ & $r$ & $P$ & $r$ & $P$ \\
\hline $\begin{array}{l}\text { Carbohydrate oxidation }(\mathrm{kJ} / \mathrm{min}) v \text {. carbohydrate intake }(\mathrm{kJ}) \\
\text { Lipid oxidation }(\mathrm{kJ} / \mathrm{min}) v \text {. lipid intake }(\mathrm{kJ})\end{array}$ & $\begin{array}{l}0.09 \\
0.34\end{array}$ & $\begin{array}{l}0.76 \\
0.24\end{array}$ & $\begin{array}{l}0.56 \\
0.11\end{array}$ & $\begin{array}{l}0.04 \\
0.71\end{array}$ & $\begin{array}{l}0.56 \\
0.09\end{array}$ & $\begin{array}{l}0.04 \\
0.76\end{array}$ \\
\hline
\end{tabular}


The overfeeding generally observed in the laboratory when subjects have ad libitum access to a variety of foods (Rising et al. 1992; Larson et al. 1995a) could be the result of the spontaneous overdrive of humans to eat more when food is offered ad libitum. In a buffet-type meal, a variety of foods is necessary for the determination of differences in diet composition and macronutrient selection patterns of humans. On the other hand, a wide variety of foods could lead to an increase in food intake (Larson et al. 1995a,b). In that respect, we tried to use a reasonable variety of foods to be able to detect macronutrient preferences but we observed that this variety of foods was probably sufficient to increase spontaneous food intake. Indeed, energy intake during a buffet was about $7000 \mathrm{~kJ}$ in a recent study (Imbeault et al. 1997) and a comparable intake level was recorded in the present study, which is close to the estimated average daily energy intake of these subjects (about $10500 \mathrm{~kJ} / \mathrm{d}$, about 1.4-fold their resting metabolic rate), indicating that subjects ate more than under free-living conditions. This spontaneous overfeeding could be a limitation of the use of a buffet-type meal in a context where the measurement of representative daily energy intake is important.

The context of a buffet-type meal permits assessment of the physiological effects of food intake on RQ, REE and substrate oxidation rates that demonstrated significant reproducibility between the two sessions of buffet-type meals (inter-reproducibility) and also between individual measurements (intra-subject reproducibility). Food intake increased respiratory exchange ratios from approximately 0.82 before the buffet to 0.93 immediately after the buffet which favoured a decrease in the rate of lipid oxidation and a rise in the rate of carbohydrate oxidation. It is known that a relative increase in total oxidation rates results in a decrease in food intake, whereas a diminution stimulates energy intake (Friedman, 1990). In the present study, preprandial levels of carbohydrate and fat oxidation were not predictors of subsequent macronutrient intake. According to Stubbs et al. (Stubbs et al. 1993, 1997), this may mean that variations in macronutrient stores, particularly carbohydrate, were not a significant determinant of ad libitum energy intake in the present experimental context. Moreover, as previously documented by other investigators (Thomas et al. 1992; Westerterp, 1993) lipid intake did not correlate with lipid oxidation after the buffet $(P>0.05)$, but carbohydrate intake correlated with postprandial carbohydrate oxidation $(P<0.05)$. This agrees with the concept that the body does not acutely adjust lipid oxidation to lipid intake but adjusts more rapidly carbohydrate oxidation to carbohydrate intake (Flatt et al. 1985; Westerterp, 1993). The absence of a significant relationship between lipid intake and lipid oxidation suggests that overfeeding with lipid is channelled to fat stores and this possibly leads to weight gain. This is supported by the fact that lipid oxidation was reduced after the buffet in contrast to carbohydrate oxidation which was increased, which is also concordant with results reported by other investigators (Flatt et al. 1985; Larson et al. 1995a,b).

In summary, energy and macronutrient intake, RQ, REE and substrate oxidation showed significant reproducibility under controlled conditions using a buffet-type meal in male subjects. A buffet-type meal can thus be considered as a reliable, accurate and sensitive test to assess the ad libitum food intake of healthy men with normal body weight when there is free access to food. Furthermore, the buffet-type meal could be useful for experimental testing of the effects of preload test meals on subsequent food intake.

\section{Acknowledgement}

This study was supported by NSERC of Canada.

\section{References}

Bellisle F, Blundell JE, Dye L, Fantino M, Fern E, Fletcher RJ, Lambert J, Roberfroid M, Specter S, Westenhofer J \& WesterterpPlantenga MS (1998) Functional food science and behaviour and psychological functions. British Journal of Nutrition 80, S173S193.

Cook CG, Andrews JM, Jones KL, Wittert GA, Chapman IM, Morley JE \& Horowitz M (1997) Effects of small intestinal nutrient infusion on appetite and pyloric motility are modified by age. American Journal of Physiology 273, R755-R761.

Flatt JP (1995a) Body composition, respiratory quotient, and weight maintenance. American Journal of Clinical Nutrition 62, 1107S-1117S.

Flatt JP (1995b) Use and storage of carbohydrate and fat. American Journal of Clinical Nutrition 61, 952S-959S.

Flatt JP, Ravussin E, Acheson KJ \& Jéquier E (1985) Effects of dietary fat on postprandial substrate oxidation and on carbohydrate and fat balances. Journal of Clinical Investigation 76, 1019-1024.

Friedman MI (1990) Body fat and the metabolic control of food intake. International Journal of Obesity 3, 53-66.

Horton TJ, Drougas H, Brachey A, Reed GW, Peters JC \& Hill JO (1995) Fat and carbohydrate overfeeding in humans: different effects on energy storage. American Journal of Clinical Nutrition 62, 19-29.

Imbeault P, Saint-Pierre S, Almeras N \& Tremblay A (1997) Acute effects of exercise on energy intake and feeding behaviour. British Journal of Nutrition 77, 511-521.

Jéquier E, Acheson K \& Schutz Y (1987) Assessment of energy expenditure and fuel utilization in man. Annual Review of Nutrition 7, 187-208.

Larson DE, Rising R, Ferraro RT \& Ravussin E (1995a) Spontaneous overfeeding with a 'cafeteria diet' in men: effects on 24hour energy expenditure and substrate oxidation. International Journal of Obesity 19, 331-337.

Larson DE, Tataranni PA, Ferraro RT \& Ravussin E (1995b) Ad libitum food intake on a 'cafeteria diet' in Native American women: relations with body composition and 24-h energy expenditure. American Journal of Clinical Nutrition 62, 911-917.

Meneely EA \& Kaltreider NL (1949) Volume of the lung determined by helium dilution. Journal of Clinical Investigation $\mathbf{2 8}$, 129-139.

Obarzanek E \& Levitsky DA (1985) Eating in the laboratory: is it representative? American Journal of Clinical Nutrition 42, 323328.

Rising R, Alger S, Boyce V, Seagle H, Ferraro R, Fontvieille AM \& Ravussin E (1992) Food intake measured by an automated food-selection system: relationship to energy expenditure. American Journal of Clinical Nutrition 55, 343-349.

Rolls BJ \& Hammer VA (1995) Fat, carbohydrate, and the regulation of energy intake. American Journal of Clinical Nutrition 62, 1086S-1095S.

Rolls BJ, Kim Harris S, Fischman MW, Foltin RW, Moran TH \& Stoner SA (1994) Satiety after preloads with different amounts of fat and carbohydrate: implications for obesity. American Journal of Clinical Nutrition 60, 476-487. 
Siri W (1956) The gross composition of the body. Advances in Biology and Medical Physiology 4, 239-280.

Stubbs RJ, Murgatroyd PR, Goldberg GR \& Prentice AM (1993) Carbohydrate balance and the regulation of day-to-day food intake in humans. American Journal of Clinical Nutrition 57, 897-903.

Stubbs RJ, O'Reilly LM, Johnstone AM, Harrison CL, Clark H, Franklin MF, Reid CA \& Mazlan N (1999) Description and evaluation of an experimental model to examine changes in selection between high-protein, high-carbohydrate and high-fat foods in humans. European Journal of Clinical Nutrition 53, $13-21$.

Stubbs RJ, Prentice AM \& James WP (1997) Carbohydrates and energy balance. Annals of the New York Academy of Sciences 819, 44-69.

Thomas CD, Peters JC, Reed GW, Abumrad NN, Sun M \& Hill JO
(1992) Nutrient balance and energy expenditure during ad libitum feeding of high-fat and high-carbohydrate diets in humans. American Journal of Clinical Nutrition 55, 934-942.

Tremblay A \& Saint-Pierre S (1996) The hyperphagic effect of a high-fat diet and alcohol intake persists after control for energy density. American Journal of Clinical Nutrition 63, 479-482.

Tremblay A, Sévigny J \& Leblanc C (1983) The reproducibility of a three-day dietary record. Nutrition Research 3, 819-830.

Westerterp KR (1993) Food quotient, respiratory quotient, and energy balance. American Journal of Clinical Nutrition 57, 759S-764S.

Westerterp-Plantenga MS, Ijedema MJ \& Wijckmans-Duijsens NE (1996) The role of macronutrient selection in determining patterns of food intake in obese and non-obese women. European Journal of Clinical Nutrition 50, 580-591. 